\title{
Recovery of Heart Rate Variability After Exercise Under Hot Conditions: The Effect of Relative Humidity
}

\author{
Oriol Abellán-Aynés, $\mathrm{MSc}^{1}$; Daniel López-Plaza, $\mathrm{MSc}^{1}$; Fernando Alacid, $\mathrm{PhD}^{2}$; Jose Naranjo-Orellana, $\mathrm{PhD}^{3}$; \\ Pedro Manonelles, $\mathrm{PhD}^{1}$ \\ ${ }^{1}$ Department of Sports Medicine, Catholic University of Murcia, Murcia, Spain; ${ }^{2}$ Department of Education, Health Research Centre, University of \\ Almería, Almería, Spain; ${ }^{3}$ Department of Sport and Computing, Pablo de Olavide University, Seville, Spain
}

\begin{abstract}
Introduction - The aim of this study was to analyze changes in heart rate variability (HRV) during exercise in hot environments and recovery to baseline values depending on relative humidity.

Methods-Ten recreational runners participated in this study. Each participant performed 2 trials consisting of $30 \mathrm{~min}$ of continuous running under hot and dry (HD) $\left(38^{\circ} \mathrm{C}\right.$ and $28 \%$ relative humidity) and hot and humid $(\mathrm{HH})$ conditions $\left(38^{\circ} \mathrm{C}\right.$ and $64 \%$ relative humidity) at their common $10 \mathrm{~km}$ race-running rhythm. HRV and body mass were assessed pre- and post-trial; the rating of perceived exertion and HRV were assessed during the trial; and HRV measurements were repeated 2, 4, 8, and 24 h postexercise. Primary HRV outcomes were root mean square of the successive differences, high frequency power, stress score, and sympathetic/parasympathetic ratio. One-way analysis of variance testing was used to analyze differences.

Results-No significant difference in body mass occurred across the different conditions or distances covered $(P>0.05)$. Rating of perceived exertion presented the highest correlation values with stress score $(r=0.729$ for $\mathrm{HD} ; \mathrm{r}=0.568$ for $\mathrm{HH})$ and sympathetic/parasympathetic ratio ( $\mathrm{r}=0.621$ for $\mathrm{HD}$; $\mathrm{r}=0.519$ for $\mathrm{HH}$ ) during exercise. HRV recovered to baseline values more quickly after exercising under dry conditions $(4 \mathrm{~h})$ than under humid conditions (between 8 and $24 \mathrm{~h}$ ).

Conclusions-Stress score and sympathetic/parasympathetic ratio seem to be the best HRV predictors of internal load. Although there are no differences in HRV during recovery at the same time points in both conditions, the recovery is slower after exercise in HH than in HD.
\end{abstract}

Keywords: sympathetic, parasympathetic, autonomic nervous system, hyperthermia

\section{Introduction}

Heart rate (HR) variability (HRV) has been commonly used to assess autonomic nervous system (ANS) modulation. Variables of the time domain calculated from R-R intervals (RR), such as root mean square of successive differences of RR (RMSSD) or consecutive intervals that differ by more than $50 \mathrm{~ms}$ (pNN50) are related to parasympathetic activity, and increased values of these variables are related to physical training adaptations. ${ }^{1,2}$ Additionally, frequency domain variables, including very low frequency, low frequency (LF), and high

Corresponding author: Oriol Abellán-Aynés, MSc, Catholic University of Murcia (UCAM), International Chair of Sports Medicine, Av jeronimos s/n, Murcia, Spain; e-mail: oabellan@ucam.edu.

Submitted for publication January 2019.

Accepted for publication April 2019. frequency (HF) power, may be predictors of physical fitness. ${ }^{3}$ Poincare plot analysis of HRV is also a common practice for assessment of the ANS because the standard deviation of instantaneous beat-to-beat RR interval variability (SD1) is identical to RMSSD. ${ }^{4}$ Likewise, Poincare plot variables have been used to propose new indexes for the assessment of ANS balance.

HRV has become an interesting tool for training adaptation control. ${ }^{6-10}$ In regard to endurance exercise, there is a significant decrease in HRV during exercise for athletes with higher values of maximal oxygen consumption $\left(\mathrm{VO}_{2 \max }\right)$ than for athletes with lower $\mathrm{VO}_{2 \max }$ levels. ${ }^{11,12}$ Previous research has used HRV to assess ventilatory thresholds, ${ }^{13}$ demonstrating the relationship between HRV and endurance exercise intensity. During exercise, both time and frequency domain variables decrease compared to resting values. ${ }^{14,15} \mathrm{HRV}$ values start to recover 
immediately after exercise, but baseline levels are not reached $10 \min ^{15}$ nor $60 \mathrm{~min}$ after exercise. ${ }^{16}$ The intensity of the exercise has shown to be a determinant in the time needed to reach full recovery. ${ }^{17}$ This means that the higher the exercise intensity, the more time it will take to return to baseline values. ${ }^{18,19}$ Nevertheless, exercise duration is not directly related to the recovery of HRV because different durations at the same intensity do not result in different recovery times. ${ }^{18,20}$

When performing resting measurements, heat has an important effect on HRV, with lower values in RMSSD and in the standard deviation of RR intervals, ${ }^{21}$ as well as in $\mathrm{pNN} 50^{22}$ for hot conditions. Additionally, hot environments have a direct effect on frequency domain variables, such as LF and HF power, ${ }^{23-26}$ total power (TP), and very low frequency power, ${ }^{22-24}$ showing that higher temperatures provoke a decrease in cardiac variability. Higher relative humidity ( $\mathrm{RH})$ shows increments in body, skin, and rectal temperature and HR during exercise under hot and neutral conditions ${ }^{27,28}$ but not in the rate of perceived exertion. ${ }^{28}$ The effect of RH on HRV has not been analyzed before; thus, it might be important to describe the effect RH may have on HRV.

Therefore, the aims of this study were first to analyze changes in HRV during exercise in hot environments and second to analyze recovery to baseline values depending on $\mathrm{RH}$.

\section{Methods}

\section{PARTICIPANTS}

The present study was approved by the San Antonio University of Murcia ethics committee. Ten healthy recreational runners $(28 \pm 5 \mathrm{y}$ old, $172 \pm 9 \mathrm{~cm}$ tall, $65 \pm 10 \mathrm{~kg}$, and running $39 \pm 5 \mathrm{~km} \cdot \mathrm{wk}^{-1}$ ) voluntarily participated in this study. All participants signed an informed consent form before the start of the measurements. Those under pharmacological or medical treatment were excluded from the study.

\section{PROTOCOL}

Each participant performed 2 trials on 2 different days separated by 1 week. Each trial was performed at the same time of the day (1400) in 2 different environmental conditions: a hot and dry environment (HD) with a temperature of $38^{\circ} \mathrm{C}$ and $28 \% \mathrm{RH}$ and a hot and humid (HH) environment at $38^{\circ} \mathrm{C}$ and $64 \% \mathrm{RH}$. The orders of the trials were randomly assigned for every subject. Subjects were asked not to exercise or to consume any alcohol or caffeine $24 \mathrm{~h}$ before and after both tests. Before the first trial, anthropometric measurements were assessed; body mass and stretch stature were also assessed using a balance with stadiometer (Seca 720; Hamburg, Germany). Ambient temperature and $\mathrm{RH}$ were assessed using an environmental meter Kestrel 5000 (Minneapolis, MN).

Before trials, a 10-min warm-up was carried out, consisting of lower body dynamic stretching exercises. The trials consisted of 30 min of running in both environments on a running track. For both of the trials, the athletes were asked to run at the speed they would use during a $10 \mathrm{~km}$ race and were allowed to drink water ad libitum; water intake was recorded. No specific intensity was set in order to extrapolate the results of recreational running practitioners; average speed was calculated at the end of the trial. BM was assessed before and after the test but not after posterior recovery. Every $5 \mathrm{~min}$, the participants were asked for a rating of perceived exertion (RPE) ${ }^{29}$ score from 6 to 20. HRV was assessed before each trial (Pre); during the trial; immediately after the test (Post); and 2, 4, 8, and $24 \mathrm{~h}$ after the end of the trial. Participants were asked not to practice intense exercise until the $24 \mathrm{~h}$ measurement was conducted. Pre- and post-trial and recovery measurements were carried out at $25^{\circ} \mathrm{C}$. HRV measurements were performed with the participants lying down, except during the exercise. Subjects wore a HR sensor Polar H7 (Kempele, Finland) to assess beat-to-beat recordings during the measurements. Data were analyzed during 5-min intervals according to the procedures determined by the European Society of Cardiology and the North American Society of Pacing and Electrophysiology, ${ }^{30}$ for a total 6 HRV assessments during exercise.

\section{HRV ANALYSIS}

Further examinations of HRV variables were done using the software Kubios HRV version 3.0. This software was also used to apply medium threshold filters for artifact removal if required. Time domain, frequency domain, and Poincare plot were retrieved. The variables analyzed were RR, RMSSD expressed in natural logarithm transformed values $\left(\mathrm{RMSSD}_{\mathrm{ln}}\right)$, and $\mathrm{pNN} 50$ for time domain variables. Fast Fourier transform was used to calculate the spectral components of the frequency domain. The HF power $(0.15-1.0 \mathrm{~Hz})$, LF power $(0.04-0.15 \mathrm{~Hz})$, and TP $(0.04-1.0 \mathrm{~Hz})$ components were calculated as integrals of the respective power spectral density curve. These variables were also expressed in natural logarithm transformed values $\left(\mathrm{HF}_{1 \mathrm{n}}, \mathrm{LF}_{\mathrm{ln}}\right.$, and $\mathrm{TP}_{\mathrm{ln}}$, respectively). Finally, Poincare plot variables such as SD1 and the standard deviation of continuous long-term R-R interval variability (SD2) were calculated. Stress score was analyzed by the formula $1000 \times 1 / \mathrm{SD} 2^{5}$ and was presented as a natural logarithm transformed value. Finally, sympathetic/parasympathetic ratio (S/PS) was calculated. 


\section{STATISTICS}

Statistical analyses were conducted with IBM statics SPSS v20.0 software (SPSS Inc, Chicago IL). The Shapiro-Wilk test was used to investigate normality of the data, and analysis of variance was used for paired samples to determine significant differences among measurements. The relationship between variables was analyzed by the Pearson correlation coefficient. Values of $P<0.05$ were considered significant differences. Results are expressed as mean values $\pm \mathrm{SD}$.

\section{Results}

Body mass markedly decreased after exercise in both HD and $\mathrm{HH}$, from $64.9 \pm 10.7 \mathrm{~kg}$ to $64.1 \pm 10.4 \mathrm{~kg}(P<0.05)$ and from $65.0 \pm 10.8 \mathrm{~kg}$ to $64.2 \pm 10.6 \mathrm{~kg}(P<0.05)$, respectively.

Table 1 shows the differences between HD and $\mathrm{HH}$ for distance covered and percentage decrease in BM. No significant differences between $\mathrm{HD}$ and $\mathrm{HH}(P>0.05)$ were detected for these variables. Similarly, there were no significant differences in water intake between $\mathrm{HD}$ and $\mathrm{HH}$ $(P>0.05)$.

Figure 1 shows an overview of RR during exercise and recovery, and Figure 2 shows how $\mathrm{RMSSD}_{\mathrm{ln}}, \mathrm{HF}_{\mathrm{ln}}$, Sscore $_{\mathrm{ln}}$, and S/PS ratio changed during exercise and postexercise. It may be observed as well how these variables change during recovery after the test. Note that no differences appeared among any of the variables when comparing $\mathrm{HD}$ and $\mathrm{HH}$ at the same time point $(P>0.05)$. Furthermore, Figure 3 shows the data for pNN50 for preand posttest and recovery. Data for $\mathrm{LF}_{\mathrm{ln}}$ and $\mathrm{TP}_{\mathrm{ln}}$ during the recovery period are presented in Table 2.

Table 3 shows the RPE values during exercise under both conditions at all-time points. For both conditions, RPE values in the first 5 min were significantly lower compared to 20, 25, and $30 \mathrm{~min}$ of exercise $(P<0.05)$. There were no significant differences between conditions at the same time point. In Table 4, correlations between HRV variables and RPE during exercise are presented separately for HD and HH.

\section{Discussion}

The main finding of this study was that the recovery of HRV to baseline values after exercise under hot

Table 1. Difference between HD and HH for distance covered and body mass change

\begin{tabular}{lcc}
\hline Variable & $H D$ & $H H$ \\
\hline Distance $(\mathrm{km})$ & $5.2 \pm 0.8$ & $5.2 \pm 0.9$ \\
Body mass decrease (\%) & $1.3 \pm 0.8$ & $1.3 \pm 0.9$ \\
\hline
\end{tabular}

$\mathrm{HD}$, hot and dry environment; $\mathrm{HH}$, hot and humid environment. conditions does not appear immediately. The effects of high temperatures on $\mathrm{HRV}$ are more remarkable in higher RH conditions than in drier environments, where the recovery is faster. The impact of $\mathrm{RH}$ has no effect on HRV when exercising at the same intensity under hot conditions.

Parasympathetic-related variables such as RMSSD and HF started to fall dramatically from the beginning of the exercise and then remained constant during the activity from the first $5 \mathrm{~min}$ in the frequency domain (HF) and from $10 \mathrm{~min}$ in the time domain (RMSSD). In both $\mathrm{HD}$ and $\mathrm{HH}$, all participants were asked to run at the same intensity. We did not observe any difference between trials during exercise in HRV and identified no changes in HRV during exercise under different RH conditions in hot conditions. In agreement with our results, previous research states that RMSSD and HF tended to zero during moderate intensity. ${ }^{17}$ The recovery periods for both variables were equal; values similar to baseline were identified $4 \mathrm{~h}$ after exercise in the HD environment. Conversely, under the $\mathrm{HH}$ environment, more than $4 \mathrm{~h}$ of recovery was needed. These results may imply that parasympathetic recovery takes place more quickly when the activity is done under HD conditions than under $\mathrm{HH}$ conditions. Analyzing more time domain variables, the pNN50 recovery period was even longer after exercise under the $\mathrm{HH}$ environment, with significantly lower values in pNN50 after $8 \mathrm{~h}$ of recovery compared to baseline values. Other authors did not observe significant recovery of $\mathrm{HF}$ after $30 \mathrm{~min}^{31}$ or of RMSSD and HF after 60 min of recovery. ${ }^{16}$ On the contrary, recovery to baseline values was identified in prior investigations after continuous running at anaerobic threshold intensity after $30 \mathrm{~min}$ for RMSSD and $60 \mathrm{~min}$ for pNN50. ${ }^{18}$

Similar results have been observed for RMSSD and $\mathrm{HF}$ after interval training in the first $2 \mathrm{~h}$ of recovery, whereas different results were determined after moderate intensity endurance training. ${ }^{2}$ These data indicate that higher intensity exercise can result in a longer time needed to return to baseline values of HRV; therefore, parasympathetic activity is more susceptible to change because of the high intensity. Furthermore, higher values of RH during exercise in hot conditions seem to be related to slower recovery after exercise. TP and LF power values after continuous exercise do not return to similar baseline levels after 30 min of recovery regardless of exercise intensity. ${ }^{31}$ These results are in agreement with those presented here for $\mathrm{HH}$ but not for HD. After exercising in HD, TP values did not differ from initial values, with significantly lower values up to $2 \mathrm{~h}$ after exercise. Results in $\mathrm{LF}_{1 \mathrm{n}}$ values were similar in both HD and $\mathrm{HH}$ to those reported in previous research. ${ }^{31}$ The TP changes during exercise did not differ among different 


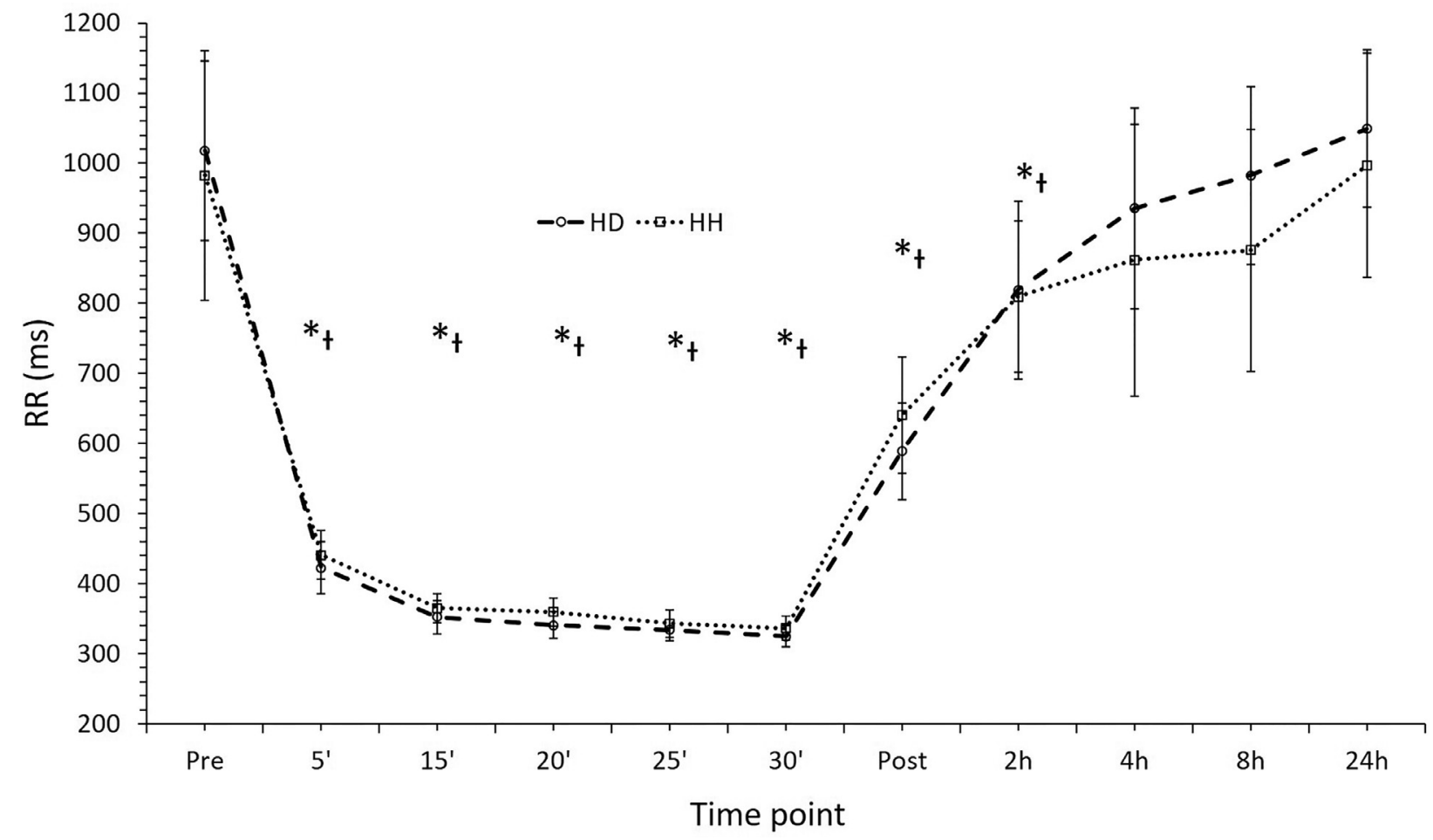

Figure 1. Changes in RR during exercise and recovery postexercise. HD, hot and dry environment; HH: hot and humid environment. Values are presented as mean $\pm \mathrm{SD}$. X-axis is a discontinuous scale. ${ }^{*} P<0.05$ from PRE for $\mathrm{HD}$. ${ }^{\dagger} P<0.05$ from PRE for $\mathrm{HH}$.
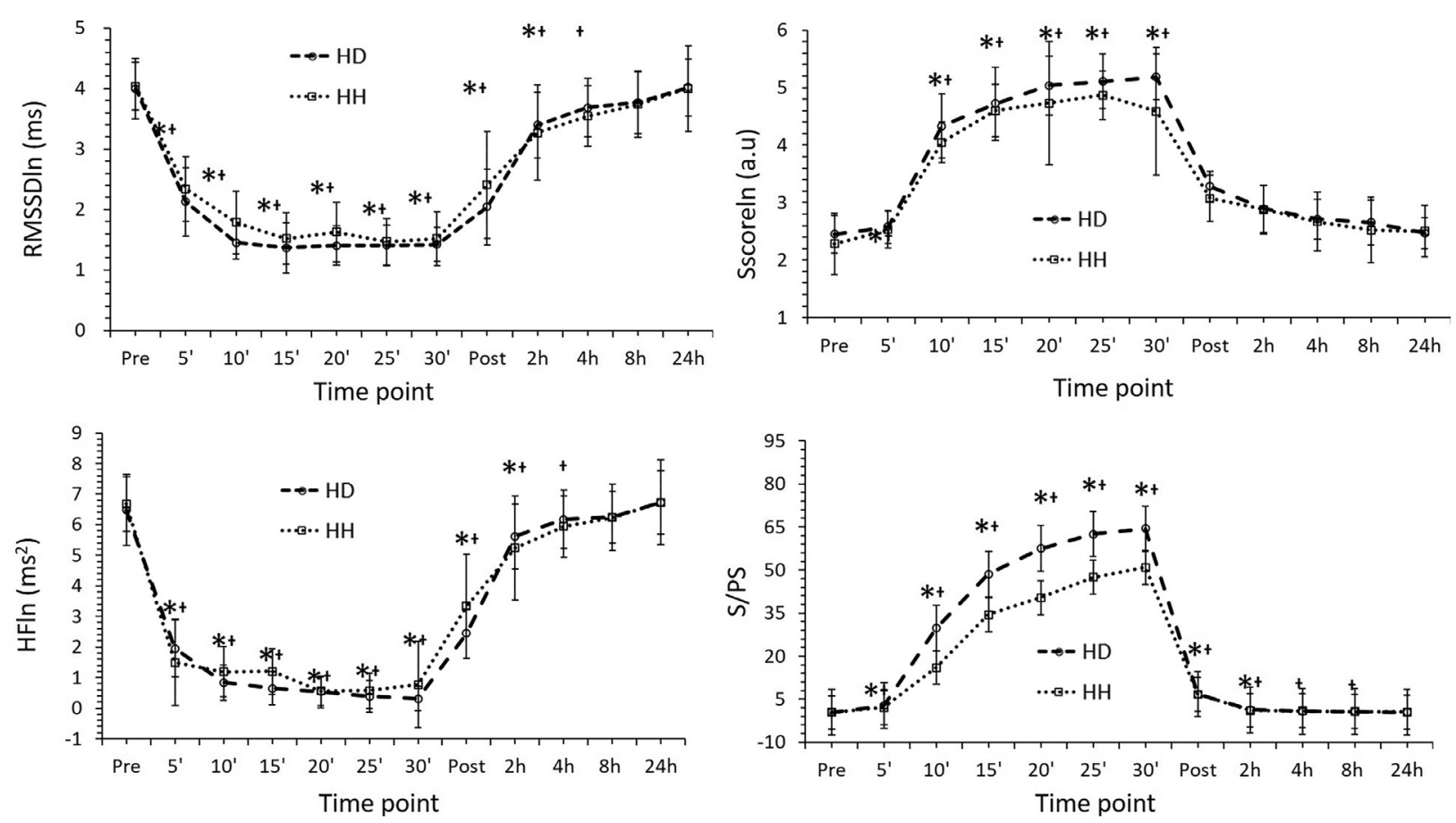

Figure 2. Changes in $\mathrm{RMSSD}_{\mathrm{ln}}, \mathrm{HF}_{\mathrm{ln}}$, Sscore $\mathrm{In}_{\mathrm{n}}$, and $\mathrm{S} / \mathrm{PS}$ during exercise and recovery postexercise. Values are presented as mean $\pm \mathrm{SD}$. X-axis is a discontinuous scale. $\mathrm{HD}$, hot and dry environment; $\mathrm{HH}$, hot and humid environment. $* P<0.05$ from PRE for HD. ${ }^{\dagger} P<0.05$ from PRE for HH. 


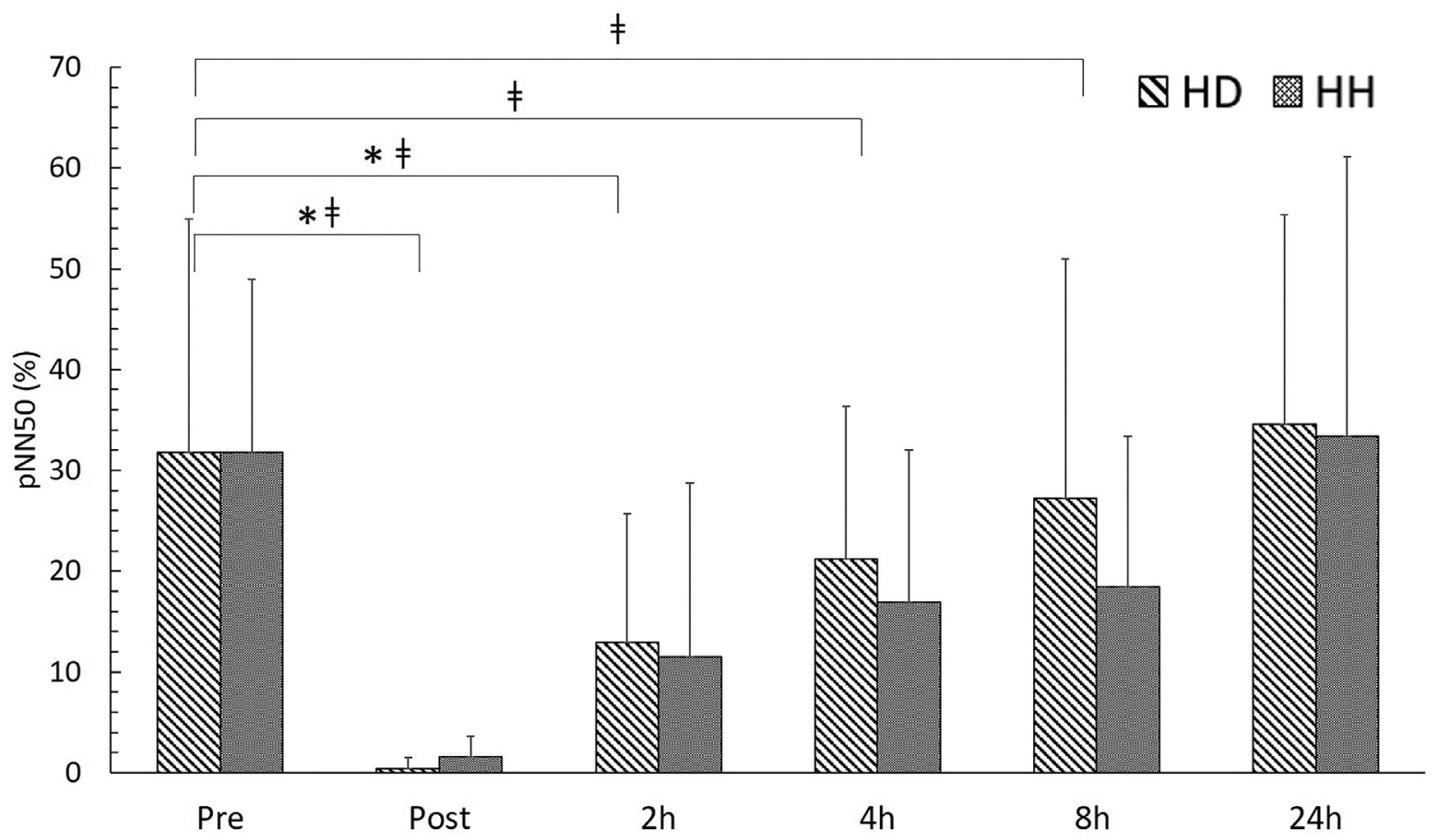

Figure 3. Changes in pNN50 pre- and postexercise and during recovery. pNN50: consecutive intervals that differ by more than 50 ms. HD, hot and dry environment; $\mathrm{HH}$, hot and humid environment. ${ }^{*} P<0.05$ for $\mathrm{HD} .{ }^{\dagger} P<0.05$ for $\mathrm{HH}$.

intensities $^{32}$; however, our results showed a greater effect on TP during recovery after exercise under $\mathrm{HH}$ than for HD conditions.

Previous research ${ }^{7,18,33,34}$ identified that exercise duration had no effect on time and frequency domain changes. Time and frequency domain variables remained constant during exercise. On the contrary, S/PS did not

Table 2. Recovery period after exercise for $\mathrm{LF}_{\ln }$ and $\mathrm{TP}_{\ln }$

\begin{tabular}{lllr}
\hline Environment & Time point & $L F_{l n}\left(\mathrm{~ms}^{2}\right)$ & $T P_{l n}\left(\mathrm{~ms}^{2}\right)$ \\
\hline & PRE & $6.8 \pm 0.8$ & $6.6 \pm 3.2$ \\
& POST & $4.7 \pm 1.2^{a}$ & $6 \pm 0.7$ \\
$\mathrm{HD}$ & $2 \mathrm{~h}$ & $6.1 \pm 0.7^{a}$ & $5.1 \pm 3.1$ \\
& $4 \mathrm{~h}$ & $6.4 \pm 1.0$ & $6.3 \pm 3.1$ \\
& $8 \mathrm{~h}$ & $6.6 \pm 0.7$ & $6.4 \pm 2.8$ \\
& $24 \mathrm{~h}$ & $6.8 \pm 0.6$ & $6.8 \pm 2.6$ \\
\hline & PRE & $7 \pm 0.8$ & $7.6 \pm 1.8$ \\
& POST & $5.4 \pm 1.5^{a}$ & $4.4 \pm 2.9^{a}$ \\
& $2 \mathrm{~h}$ & $6.1 \pm 1.4^{a}$ & $6.5 \pm 2.3^{a}$ \\
$\mathrm{HH}$ & $4 \mathrm{~h}$ & $6.8 \pm 1.0$ & $6.2 \pm 3.0$ \\
& $8 \mathrm{~h}$ & $6.9 \pm 1.0$ & $6.5 \pm 2.6$ \\
& $24 \mathrm{~h}$ & $6.8 \pm 1.4$ & $6 \pm 3.6$ \\
\hline
\end{tabular}

$\mathrm{LF}_{\mathrm{ln}}$, low frequency natural logarithm; $\mathrm{TP}_{\mathrm{ln}}$, total power natural logarithm; HD, hot and dry environment; PRE, pretrial; POST, post-trial; $\mathrm{HH}$, hot and humid environment.

${ }^{a} P<0.05$ from PRE. remain stable during exercise; it increased during the whole trial and did not reach a specific limit. Future research might study how long S/PS can continue increasing in relation to exercise intensity and duration. S/PS returned to baseline values faster in HD than for $\mathrm{HH}$ conditions, showing that higher ambient RH produces a greater impact on sympathetic activity during high temperatures. This effect was higher than in time and frequency domains; after $8 \mathrm{~h}$ of recovery after $\mathrm{HH}$ conditions, S/PS baseline values were not reached, whereas baseline was reached in less than $4 \mathrm{~h}$ after exercise in HD conditions. Unfortunately, acute effects on Sscore and S/PS after exercise have not been deeply analyzed in previous studies. No differences among HD and HH conditions were observed during recovery in Sscore. Results were not different from baseline immediately after the exercise; thus, Sscore did not yield any information on differences in the recovery period after exercise in HD and $\mathrm{HH}$ conditions. Sscore during exercise markedly increased in the first $10 \mathrm{~min}$, and at minute 15 it remained constant until the end of the exercise, with a decrement in the last $5 \mathrm{~min}$ of exercise. Even though significant differences appear in the HRV recovery under humid environments, these differences do not exist at the same time point of recovery. Significance does not always indicate meaningfulness, however, so future research should study this effect of RH under hot conditions with regard to intensity of exercise and controlling 
Table 3. RPE values during exercise under $\mathrm{HD}$ and $\mathrm{HH}$

\begin{tabular}{lcr}
\hline Time point $(\mathrm{min})$ & $H D$ & \multicolumn{1}{c}{$H H$} \\
\hline 5 & $8.1 \pm 2.7$ & $7.1 \pm 1.7$ \\
10 & $9.3 \pm 2.3$ & $8.3 \pm 1.6$ \\
15 & $10.7 \pm 2.3$ & $9.5 \pm 2.5$ \\
20 & $12.9 \pm 2.3$ & $11.5 \pm 2.8$ \\
25 & $14.1 \pm 2.0$ & $12.9 \pm 2.8$ \\
30 & $15.7 \pm 1.6$ & $14.5 \pm 3.1$ \\
\hline
\end{tabular}

RPE, rate of perceived exertion; HD, hot and dry environment; HH, hot and humid environment.

for a longer acute effect. This way, more consistent results regarding the effect of $\mathrm{RH}$ could be retrieved.

Although we have observed that exercising under $\mathrm{HH}$ conditions leads to a faster recovery than HD for ANS, RPE did not differ between conditions during exercise. Additionally, RPE showed an identical increment tendency, with the same differences intratrial in both tests. The relationship between RPE and HRV has been previously described. High correlations were observed between RPE and HF, LF, and $\mathrm{TP},{ }^{7,9}$ revealing results similar to those reported in HD; this was true only for TP values in $\mathrm{HH}$ conditions. Higher correlations with RPE were observed for RR; these results are predictable because RR is proportional to $\mathrm{HR}$ (HR) ( $\mathrm{RR}=60 / \mathrm{HR}$ ), and $\mathrm{HR}$ presents high correlations with RPE. ${ }^{35,36}$ In addition, Sscore presented a high correlation value with RPE, as seen in Table 4, which may suggest that Sscore is the best predictor of internal load during exercise if we compare its values to values obtained in the time and frequency domain variables in the correlation with RPE. Sscore presented the highest correlation value with RPE for both $\mathrm{HD}$ and $\mathrm{HH}$, but a higher value was obtained for $\mathrm{HD}$. We

Table 4. Correlation indexes between HRV and RPE

\begin{tabular}{lccccc}
\hline & \multicolumn{2}{c}{$H D$} & & \multicolumn{2}{c}{$H H$} \\
\cline { 2 - 3 } \cline { 5 - 6 } Domain & $r$ & $\mathrm{P}$ & & $r$ & $\mathrm{P}$ \\
\hline $\mathrm{RR}$ & -0.757 & 0.000 & & -0.763 & 0.000 \\
SDNN & -0.538 & 0.000 & -0.384 & 0.004 \\
$\mathrm{HF}_{\text {ln }}$ & -0.532 & 0.000 & -0.241 & 0.079 \\
$\mathrm{LF}_{\text {ln }}$ & -0.572 & 0.000 & -0.150 & 0.280 \\
$\mathrm{TP}_{\text {ln }}$ & -0.671 & 0.000 & -0.466 & 0.000 \\
Sscore & 0.729 & 0.000 & & 0.568 & 0.000 \\
S_PS & 0.621 & 0.000 & 0.519 & 0.000 \\
\hline
\end{tabular}

$\mathrm{HRV}$, heart rate variability; RPE, rate of perceived exertion; HD, hot and dry environment; $\mathrm{HH}$, hot and humid environment; RR, R-R intervals; SDNN, standard deviation of N-N intervals; $\mathrm{HF}_{\mathrm{ln}}$, high frequency natural logarithm; $\mathrm{LF}_{\mathrm{ln}}$, low frequency natural logarithm; $\mathrm{TP}_{\mathrm{ln}}$, total power natural logarithm. suppose the fact that Sscore and S/PS ratio presented higher values in the correlation with RPE might be due to the tendency to zero time and frequency domain variables during exercise whereas Sscore and S/PS continued to increase with behavior similar to RPE.

Body mass decreased significantly in both runs, but there were no differences between them. Prior researchers obtained similar results when comparing exercise at $23 \%$ RH to $43 \%, 52 \%$, and $61 \%$ RH. ${ }^{27}$ Conversely, these authors observed significantly higher values in tympanic temperature when exercising at $71 \%$ RH compared to $23 \%$. $^{27}$ Thus, higher values of $\mathrm{RH}$ would be needed to observe a higher increment in tympanic temperature between trials.

\section{LIMITATIONS OF THE STUDY}

In this study, exercise intensity was not controlled. As seen, intensity has a direct effect on HRV; thus, further research should establish a certain intensity. Furthermore, there was a lack of core and skin temperature data, which would have been useful to interpret why higher humidity provokes this response on HRV.

\section{Conclusions}

HRV does not behave differently during exercise in hot conditions depending on $\mathrm{RH}$. The recovery of initial values of HRV does not happen immediately after exercise; the time needed to return to baseline levels may be up to $8 \mathrm{~h}$. Higher RH may lead to a slower recovery of ANS modulation after continuous exercise under high-temperature conditions. The recovery to baseline conditions for practitioners took longer after endurance exercise $\mathrm{HH}$ conditions than in HD conditions. On the other hand, Sscore appeared to be significant in the assessment of internal load based on the relationship with RPE.

Author Contributions: Study concept and design (OAA); acquisition of the data (OAA, DLP); analysis of data (OAA, FA, PM, JNO); manuscript writing (OAA, DLP); critical revision of the manuscript (PM, FA, JNO); reading and approval of the final manuscript (OAA, DLP, FA, JNO, PM).

Financial/Material Support: None.

Disclosures: None.

\section{References}

1. Melanson EL, Freedson PS. The effect of endurance training on resting heart rate variability in sedentary adult males. Eur J Appl Physiol. 2001;85(5):442-9.

2. Perkins SE, Jelinek HF, Al-Aubaidy HA, de Jong B. Immediate and long term effects of endurance and high intensity interval exercise on linear and nonlinear heart rate variability. J Sci Med Sport. 2017;20(3):312-6. 
3. Sacknoff DM, Gleim GW, Stachenfeld N, Coplan NL. Effect of athletic training on heart rate variability. Am Heart J. 1994;127(5):1275-8.

4. Ciccone AB, Siedlik JA, Wecht JM, Deckert JA, Nguyen ND, Weir JP. Reminder: RMSSD and SD1 are identical heart rate variability metrics. Muscle Nerve. 2017;56 (4):674-8.

5. Naranjo-Orellana J, de la Cruz Torres B, Sarabia Cachadina E, de Hoyo M, Dominguez Cobo S. Two new indexes for the assessment of autonomic balance in elite soccer players. Int J Sport Physiol. 2015;10(4):452-7.

6. Buchheit M, Chivot A, Parouty J, Mercier D, Al Haddad H, Laursen $\mathrm{P}$, et al. Monitoring endurance running performance using cardiac parasympathetic function. Eur J Appl Physiol. 2010;108(6):1153-67.

7. Kaikkonen P, Hynynen E, Mann T, Rusko H, Nummela A. Can HRV be used to evaluate training load in constant load exercises. Eur J Appl Physiol. 2010;108(3):435-42.

8. Chalencon S, Busso T, Lacour J-R, Garet M, Pichot V, Connes $\mathrm{P}$, et al. A model for the training effects in swimming demonstrates a strong relationship between parasympathetic activity, performance and index of fatigue. PloS One. 2012;7(12):e52636.

9. Kaikkonen P, Hynynen E, Mann T, Rusko H, Nummela A. Heart rate variability is related to training load variables in interval running exercises. Eur J Appl Physiol. 2012;112 (3):829-38.

10. Saboul D, Balducci P, Millet G, Pialoux V, Hautier C. A pilot study on quantification of training load: the use of HRV in training practice. Eur J Sport Sci. 2016;16(2):172-81.

11. D’Agosto T, Peçanha T, Bartels R, Moreira D, Silva L, Nóbrega A, et al. Cardiac autonomic responses at onset of exercise: effects of aerobic fitness. Int J Sport Med. 2014;35 (10):879-85.

12. Boullosa DA, Nakamura FY, Perandini LA, Leicht AS. Autonomic correlates of Yo-Yo performance in soccer referees. Motriz. 2012;18(2):291-7.

13. Ramos-Campo DJ, Rubio-Arias JA, Ávila-Gandía V, Marín-Pagán C, Luque A, Alcaraz PE. Heart rate variability to assess ventilatory thresholds in professional basketball players. J Sport Health Sci. 2016;6(4):468-73.

14. Yamamoto Y, Hughson RL, Peterson JC. Autonomic control of heart rate during exercise studied by heart rate variability spectral analysis. J Appl Physiol (1985). 1991;71 (3):1136-42.

15. Michael S, Jay O, Halaki M, Graham K, Davis GM. Submaximal exercise intensity modulates acute post-exercise heart rate variability. Eur J Appl Physiol. 2016;116 (4):697-706.

16. Almeida AC, Machado AF, Albuquerque MC, Netto LM, Vanderlei FM, et al. The effects of cold water immersion with different dosages (duration and temperature variations) on heart rate variability post-exercise recovery: a randomized controlled trial. J Sci Med Sport. 2016;19 (8):676-81.

17. Michael S, Graham KS, Davis GM. Cardiac autonomic responses during exercise and post-exercise recovery using heart rate variability and systolic time intervals-a review. Front Physiol. 2017;8:301.

18. Seiler S, Haugen O, Kuffel E. Autonomic recovery after exercise in trained athletes: intensity and duration effects. Med Sci Sports Exerc. 2007;39(8):1366-73.

19. Niewiadomski W, Gąsiorowska A, Krauss B, Mroz A, Cybulski G. Suppression of heart rate variability after supramaximal exertion. Clin Physiol Funct Imaging. 2007;27(5):309-19.

20. Casonatto J, Tinucci T, Dourado AC, Polito M. Cardiovascular and autonomic responses after exercise sessions with different intensities and durations. Clinics. 2011;66(3):453-8.

21. Peçanha T, de Moraes Forjaz CL, Low DA. Additive effects of heating and exercise on baroreflex control of heart rate in healthy males. J Appl Physiol (1985). 2017;123(6):1555-62.

22. Brenner I, Thomas S, Shephard R. Spectral analysis of heart rate variability during heat exposure and repeated exercise. Eur J Appl Physiol. 1997;76(2):145-56.

23. Sollers JJ, Sanford TA, Nabors-Oberg R, Anderson CA, Thayer JF. Examining changes in HRV in response to varying ambient temperature. IEEE Eng Med Biol Mag. 2002;21(4):30-4.

24. Yamamoto S, Iwamoto M, Inoue M, Harada N. Evaluation of the effect of heat exposure on the autonomic nervous system by heart rate variability and urinary catecholamines. J Occup Health. 2007;49(3):199-204.

25. Kamath MV, Fallen EL. Power spectral analysis of heart rate variability: a noninvasive signature of cardiac autonomic function. Crit Rev Biomed Eng. 1993;21(3):245311.

26. Kleiger RE, Miller JP, Bigger JT, Moss AJ. Decreased heart rate variability and its association with increased mortality after acute myocardial infarction. Am J Cardiol. 1987;59(4):256-62.

27. Che Muhamed AM, Atkins K, Stannard SR, Mündel T, Thompson MW. The effects of a systematic increase in relative humidity on thermoregulatory and circulatory responses during prolonged running exercise in the heat. Temperature (Austin). 2016;3(3):455-64.

28. do Nascimento MA, Guilherme FR, Ferreira SA, Januário RS, Ribeiro AS, Mayhew JL, et al. Hydration status, sweating rate, heart rate and perceived exertion after running sessions in different relative humidity conditions: a randomized controlled trial. Rev Bras Cienc Sport. 2018 Nov 19. [Epub ahead of print].

29. Borg GA. Perceived exertion. Exerc Sport Sci Rev. 1974;2:131-53.

30. Camm AJ, Malik M, Bigger J, Breithardt G, Cerutti S, Cohen R, et al. Heart rate variability: standards of measurement, physiological interpretation and clinical use. Task Force of the European Society of Cardiology and the North American Society of Pacing and Electrophysiology. Circulation. 1996;93(5):1043-65.

31. Kaikkonen P, Rusko H, Martinmäki K. Post-exercise heart rate variability of endurance athletes after different highintensity exercise interventions. Scand J Med Sci Sports. 2008;18(4):511-9. 
32. Boettger S, Puta C, Yeragani VK, Donath L, Mueller H-J, Gabriel HH, et al. Heart rate variability, QT variability, and electrodermal activity during exercise. Med Sci Sports Exerc. 2010;42(3):443-8.

33. Kaikkonen P, Nummela A, Rusko H. Heart rate variability dynamics during early recovery after different endurance exercises. Eur J Appl Physiol. 2007;102(1):79-86.

34. Moreno IL, Pastre CM, Ferreira C, de Abreu LC, Valenti VE, Vanderlei LCM. Effects of an isotonic beverage on autonomic regulation during and after exercise. J Int Soc Sport Nutr. 2013;10(1):2.

35. Green JM, McLester JR, Crews TR, Wickwire PJ, Pritchett RC, Lomax RG. RPE association with lactate and heart rate during high-intensity interval cycling. Med Sci Sports Exerc. 2006;38(1):167-72.

36. Impellizzeri FM, Rampinini E, Coutts AJ, Sassi A, Marcora SM. Use of RPE-based training load in soccer. Med Sci Sports Exerc. 2004;36(6):1042-7. 